\title{
La recepción televisiva del fútbol peruano en Buenos Aires
}

The television reception of Peruvian football in Buenos Aires

\author{
María Soledad Balsas msbalsas@conicet.gov.ar \\ http://orcid.org/0000-0002-7456-6977 \\ Centro de Investigaciones Sociales; Instituto de \\ Desarrollo Económico y Social/ Consejo Nacional \\ de Investigaciones Científicas y Técnicas (Argentina)
}

\section{Resumen}

En el presente artículo exploro algunas de las posibilidades que ofrece lo visual para la investigación etnográfica en el ámbito de los estudios sobre medios de comunicación y migraciones internacionales en la Argentina. Luego de una breve revisión del uso que he hecho de lo visual en mis contribuciones precedentes dentro de este campo, me focalizo en las potencialidades de lo visual en la etnografía virtual a partir del análisis de un caso: la recepción televisa del fútbol transnacional peruano en Buenos Aires. Lo visual resulta valioso para lograr una comprensión más holística, aunque necesariamente parcial, de las realidades que estudiamos tanto como para ejercer cierta vigilancia epistemológica sobre nuestros propios modos de ver y de posicionarnos como investigadores.

Palabras clave: Metodología; migraciones; medios de comunicación; etnografía virtual. 
Abstract

In this article I explore some of the possibilities of the visual for ethnographic research in the context of media and international migrations studies in Argentina. After a brief review of the use I have been making of the visual in my own contributions to this field, I focus on the potential of images for virtual ethnography through the analysis of a case a study: the reception of televised Peruvian football in Buenos Aires, Argentina. I conclude that the visual is valuable to not only to achieve a better understanding of the realities we deal with, that remain necessarily partial, but also to exercise the epistemological awareness on our own viewpoints.

Keywords: Methodology; migrations; media; virtual ethnography.

Aunque existen notables excepciones, podría argumentarse que el análisis sobre medios de comunicación y migraciones internacionales en la Argentina ha tendido a concentrarse en el discurso escrito, sobre todo el de la prensa, antes que en los aspectos visuales. Podría hipotetizarse que esta situación esté relacionada con las vicisitudes propias de la gestión de los permisos correspondientes para reproducir imágenes alcanzadas por los derechos de autor, los recaudos éticos y legales que comporta el trabajo con imágenes, en particular aquéllas que involucran a personas, los desafíos teórico-metodológicos que implica así como el costo y esfuerzo adicionales y la capacidad técnica que dicho trabajo supone.

Al revisar mi proprio aporte a este campo surge que si bien las imágenes forman parte de mi interés de investigación desde hace tiempo, su potencial no ha sido hasta el momento suficientemente explorado. En el marco de mi investigación doctoral analicé los discursos sobre las migraciones internacionales que los libros de texto distribuidos por el Ministerio de Educación de la Nación disbribuyó entre 1993 y 2008 a través de los programas compensatorios que implementa (Balsas, 2013). No obstante la cantidad y diversidad de géneros visuales incluidos en los libros de texto, en esa oportunidad opté por describir las imágenes antes que reproducirlas, ya que el artículo 10 de la Ley de Propiedad Intelectual no prevé el uso -aún con fines académicos- de textos visuales incluidos en obras protegidas. De manera interesante, la ley sí contempla las citas de hasta mil palabras...(1). Y gestionar los permisos correspondientes no parecía viable.

Durante mi proyecto de investigación posdoctoral, desarrollé tres grupos de discusión focal con italianos/as e ítalo-argentinos/as residentes en Buenos Aires, entre otras técnicas desarrolladas 
(Balsas, 2018). Aquí utilicé imágenes fijas y en movimiento para dinamizar la discusión. Otros usos que hice de los medios audiovisuales en este proyecto resultan menos innovadores: utilicé la fotografía y el video también para registrar las sesiones de discusión con la finalidad de evitar perder información visual relevante, que luego transcribí verbalmente. También utilicé el video con el propósito deliberado de contar con un registro fehaciente ante eventuales controversias que pudieran surgir entre lo dicho por las y los participantes y lo transcripto y lo interpretado por mí.

En términos de Pink (2007), estos usos de lo visual estarían informados por una interpretación positivista de las ciencias sciales. En este contexto, lo visual es entendido no sólo en términos de lo observable sino también de lo inmaterial y lo sensorial relativos a la experiencia y el conocimiento humanos. Desde este punto de vista, el valor de lo visual en la investigación no se limita por cierto ni a la función "objetiva" de registro ni a la ilustración de textos escritos sino que supone formas de conocimiento inaccesibles por otras vías. Así, postula que cada modo semiótico evoca diferentes elementos del trabajo de campo: las imágenes no reemplazan necesariamente a las palabras y el análisis de lo visual producido en términos estrictamente verbales tiene escasa relevancia para esta autora. En este sentido, imágenes y palabras forman un registro necesariamente incompleto en el cual es posible reconocer diferentes niveles de representación (2).

En el ámbito del proyecto de investigación que me encuentro realizando, la necesidad de volver a pensar el rol de lo visual en la producción de conocimiento se volvió a presentar. En esta oportunidad, el foco está puesto en la recepción televisiva del fútbol transnacional entre migrantes de diversos grupos, ya sea en términos de origen nacional, lingüísticos, etcétera. Durante la primera etapa de la investigación, me valí de la etnografía en ambientes virtuales, saturados de imágenes. Desde entonces comencé a advertir cierta incongruencia entre el objeto de interés y el modo de abordarlo. Si bien incluí algunas imágenes, el trabajo de campo sobre la recepción del fútbol gallego e italiano resultó prevalentemente escrito. En este contexto, una inquietud se volvió cada vez más acuciante: ¿hasta qué punto es posible producir conocimiento sobre la recepción televisiva sin problematizar lo visual como modo de conocimiento?

Junto a las cuestiones epistemológicas antes planteadas, se impuso la necesidad política de hacer "visible" mis propias investigaciones. En un contexto en que nuestra contribución como cientistas sociales es cuestionada, cambiar de registro no sólo para "mostrar" lo que hacemos sino también para pensar en, con y a través de imágenes me pareció muy atinado. La proliferación de ciertos discursos basados en imágenes protagonizadas por migrantes me 
interpeló a buscar formas alternativas de producción de conocimiento tendientes hacia una mayor incidencia del pensamiento crítico sobre los escenarios visuales que pueblan nuestra contemporaneidad global. A continuación, propongo reflexionar sobre las cuestiones hasta aquí esbozadas a partir del análisis de diversas imágenes extraídas de grupos en Facebook que nuclean a las y los simpatizantes del equipo peruano en el campeonato mundial de fútbol.

Este artículo se inscribe en el marco del proyecto de investigación "Migraciones internacionales y medios de comunicación en la Argentina. La televisión transnacional entre el estar 'aquí' y el 'allá', que desarrollo bajo la dirección del Doctor Sergio Caggiano en el Centro de Investigaciones Sociales (CIS) del Instituto de Desarrollo Económico y Social (IDES) gracias al financiamiento otorgado por el Consejo Nacional de Investigaciones Científicas y Técnicas.

\section{Análisis del corpus}

Ante la pregunta por dónde empezar a "mirar", Pink ofrece esta clave de respuesta:

[...] La primera fase del proceso de investigación puede ser una exploración interactiva de sitios web y correos electrónicos donde los elementos de la cultura visual de una determinada área estén representados. [...]. En algunos casos, un análisis de escritorio basado en páginas web constituyen el primer estadío del trabajo de campo etnográfico (2007: 45).

La etnografía virtual surgió en el seno de los estudios anglosajones sobre internet a mediados de la década de los noventa con la finalidad de comparar diferentes grupos que existen en ambientes virtuales simultáneamente. Se focaliza en la conectividad y la multisituacionalidad en diferentes ambientes a partir de un tema común. Incluye desde rápidos comentarios, extensos diálogos, elaboradas discusiones hasta artículos e intervenciones (audio)visuales a través de las cuales se hace referencia a programas, géneros, redes y plataformas televisivas que estructuran sectores reconocibles de la web, constituyendo el centro de una serie de prácticas discursivas (Barra, Tarantino y Tosoni, 2011). Al igual que los estudios etnográficos clásicos (Guber, 2005), este enfoque se basa en la flexibilidad y la observación constante y repetida en el tiempo.

Si bien todavía no había leído a Pink cuando comencé el trabajo de campo virtual hacia mediados de 2017, intuitivamente encontré en la web un espacio propicio para adentrarme en un ámbito semiótico con el que, acaso por mi condición de género, no estaba familiarizada. Me 
focalicé en Facebook porque luego de una búsqueda exploratoria identifiqué diversos espacios que reúnen a los migrantes residentes en Buenos Aires. Seleccioné páginas y grupos, abiertos y cerrados, para cada caso a analizar teniendo en cuenta: a. la cantidad de inscriptos; b. el grado de participación de los miembros; c. los intereses de los participantes; y d. el tipo de intercambios entre ellos. Leí las entradas publicadas en cada grupo siguiendo el criterio de saturación y prestando particular atención a las imágenes añadidas así como a los comentarios y diálogos suscitados a partir de cada entrada. Compilé todos aquellos que consideré podrían resultar potencialmente significativos a los fines de mi investigación. Sobre esta base, atendí a la intensidad discursiva, entendida como los intercambios registrados que permite establecer comparaciones con otros espacios del campo etnográfico estableciendo núcleos de interés centrales y periféricos. Así, fui definiendo progresivamente los "conceptos sensibilizantes", es decir, las áreas genéricas de interés que orientaron el análisis.

Por entonces, de los cinco grupos de peruanos en Buenos Aires hallados, sólo uno registraba información de interés sobre el fútbol transnacional. Es un grupo público que contaba con 25.316 miembros que evidenciaban un bajísimo interés por el fútbol: identifiqué sólo ocho entradas publicadas por cuatro personas, dos de las cuales eran mujeres. Las principales modalidades de participación eran a través del posteo de noticias y promociones muy populares publicadas por otros medios, generalmente digitales: deperu.com, digitalperu.com, solonosotrasconsejo.com. La televisión abierta peruana así como las cadenas transnacionales de fútbol estaban totalmente ausentes. Los temas abarcaban el reclutamiento de un niño peruano por el club español Barcelona, un concurso para ganar una camiseta del club peruano Carlos Mannucci de segunda división dirigido a los residentes en Trujillo auspiciado por Cablevisión TV y la promoción de un partido entre Vallejo y Unión Huaral, también correspondiente a la segunda división peruana. Predominaban las imágenes fijas. Las reacciones a las entradas eran pocas y los comentarios alusivos, casi inexistentes.

Sin embargo, esta situación se vio modificada apenas se entrevió la posibilidad de que Perú clasificara para jugar en el campeonato mundial de fútbol después de 36 años de ausencia. Desde entonces, se multiplicaron las publicaciones de todo tipo en los diversos grupos que conformaron el corpus. Por cuestiones de espacio, haré refencia solo a algunas imágenes publicadas en los distintos grupos de Facebook analizados. Como en otros casos analizados, los grupos de Facebook aludidos pueden ser vistos como un espacio privilegiado del comentario televisivo en línea. Sin embargo, a diferencia de otros grupos, los partidos, las jugadas, los goles y, con excepción de Paolo Guerrero, los jugadores no ocuparían el centro de 
la escena. Varios elementos sugieren que antes que en el juego futbolístico, el interés descansa en los (des)encuentros entre sus simpatizantes.

Luego, es interesante observar que la ausencia de una infraestructura audiovisual adecuada que permita a las y los seguidores del seleccionado peruano de fútbol seguir todos los partidos por televisión a un costo accesible no parece estimular el consumo individual por computadora de los partidos en línea. Antes bien, en algunos casos parece reafirmar la necesidad de reunirse para ver el partido con otros, en especial en lugares públicos que generan oportunidades "comerciales" al interior de la "comunidad". Este parece ser el caso de aquéllos que no pueden acceder al paquete, en general de uso doméstico, de canales de televisión peruana satelital/por internet que ofrecen operadores presuntamente informales a cambio de un único pago en efectivo.

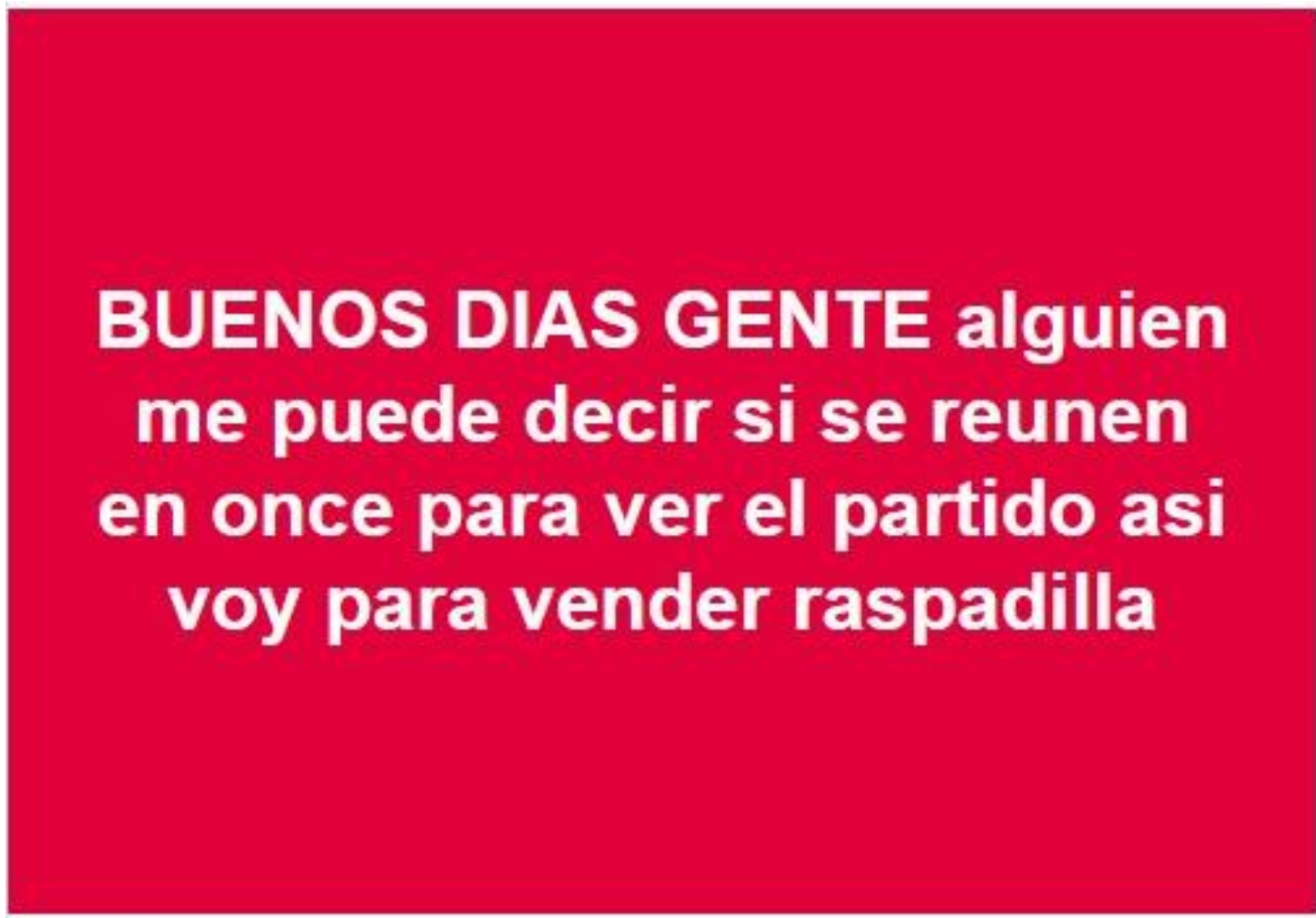

Figura 1: Captura de pantalla (5 de noviembre de 2017). Fuente: Peruanos en buenos aires [sic]. 


\section{Para la hinchada que lo mira por tevé}

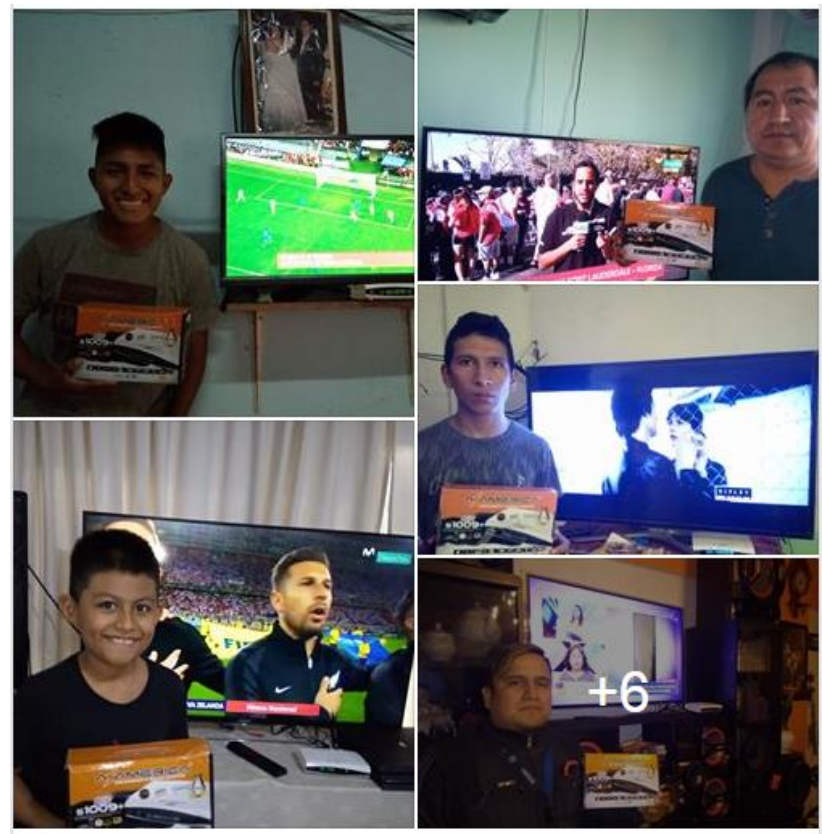

(1) $=27$

23 comentarios

Figura 2: Captura de pantalla (24 de marzo de 2018). Fuente: Peruanos en buenos aires (sic) [Página de Facebook].
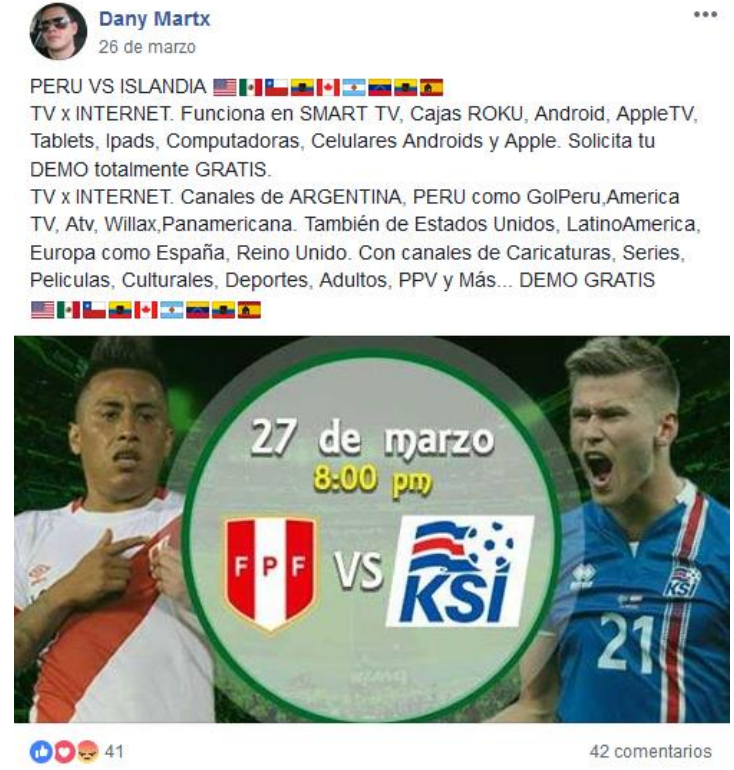

Figura 3: Captura de pantalla (26 de marzo de 2018). Fuente: Peruanos en Buenos Aires [Página de Facebook]. 


\section{Un equipo, dos hinchadas}

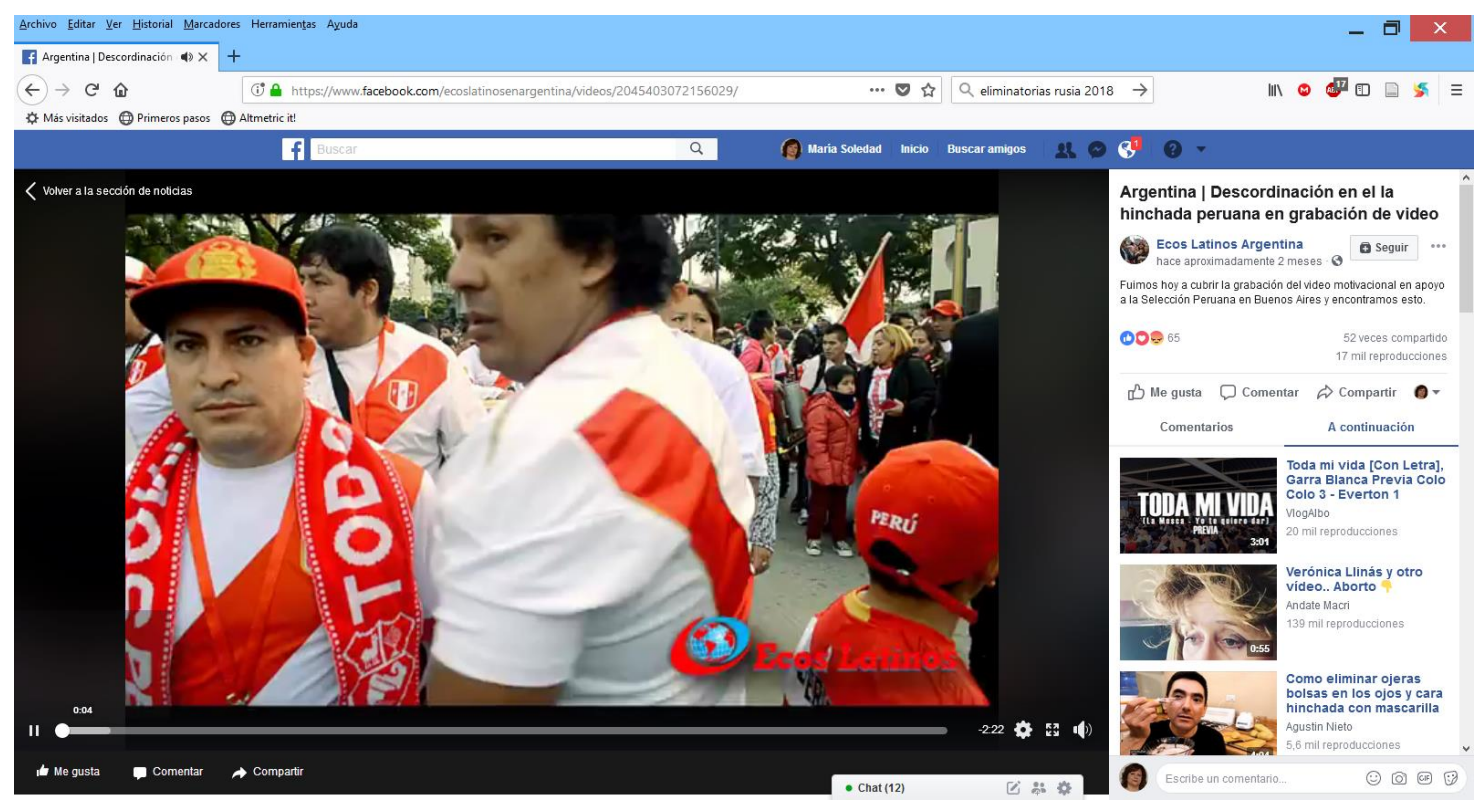

Figura 4: Captura de pantalla (20 de mayo de 2018). Fuente: Ecos Latinos [Página de Facebook].

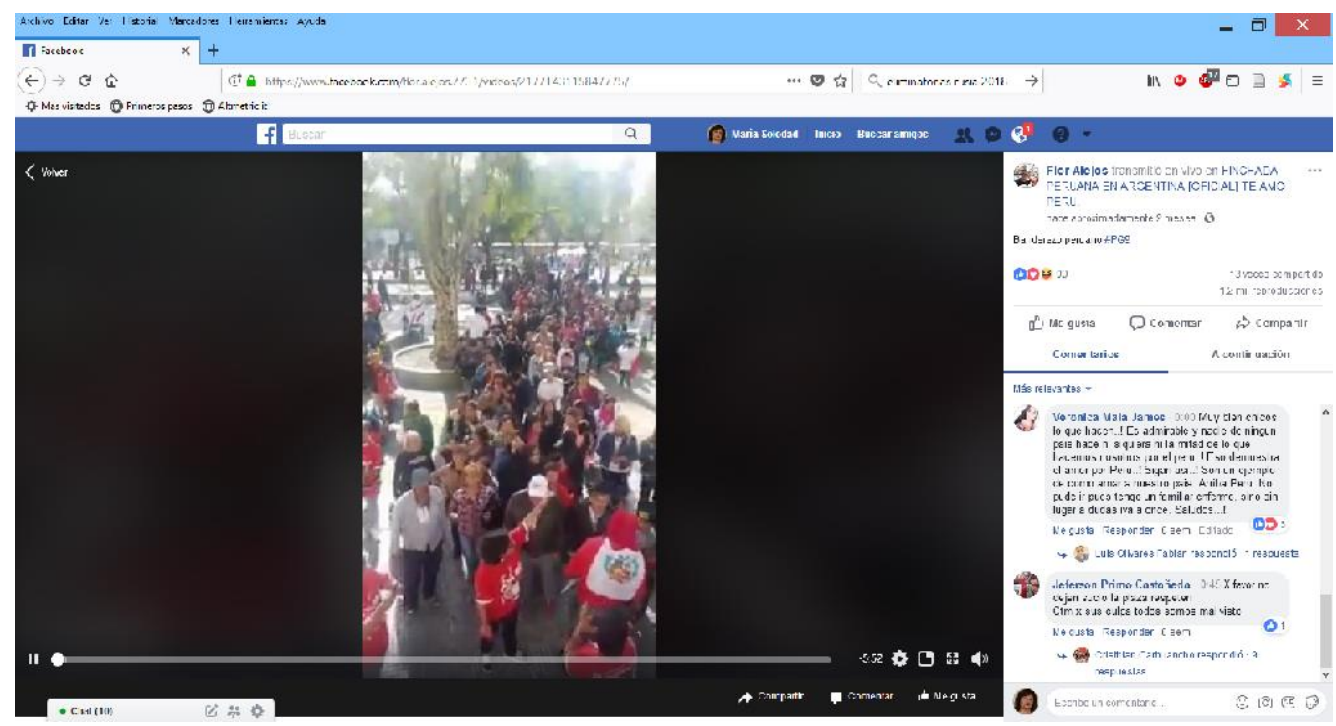

Figura 5: Captura de pantalla (20 de mayo de 2018). Fuente: HINCHADA PERUANA EN ARGENTINA [OFICIAL] TE AMO PERU [Página de Facebook]. 
El 20 de mayo se organizó un encuentro de peruanos y peruanas en la plaza del barrio Once de septiembre de la ciudad de Buenos Aires con la finalidad de "motivar" a su selección. Se trató de una iniciativa que habría tenido lugar en diversos países. El primer video se estructura como un relato periodístico que busca denunciar la división y el enfrentamiento entre ambos grupos. El segundo, más amatorial en su estilo, capta desde lo que parece ser la videocámara de un teléfono celular el momento en que varios de las y los presentes hacen fila delante de una camioneta de un empresario textil que reparte camisetas de Perú.

\section{Fútbol, televisión e imaginación comunitaria}

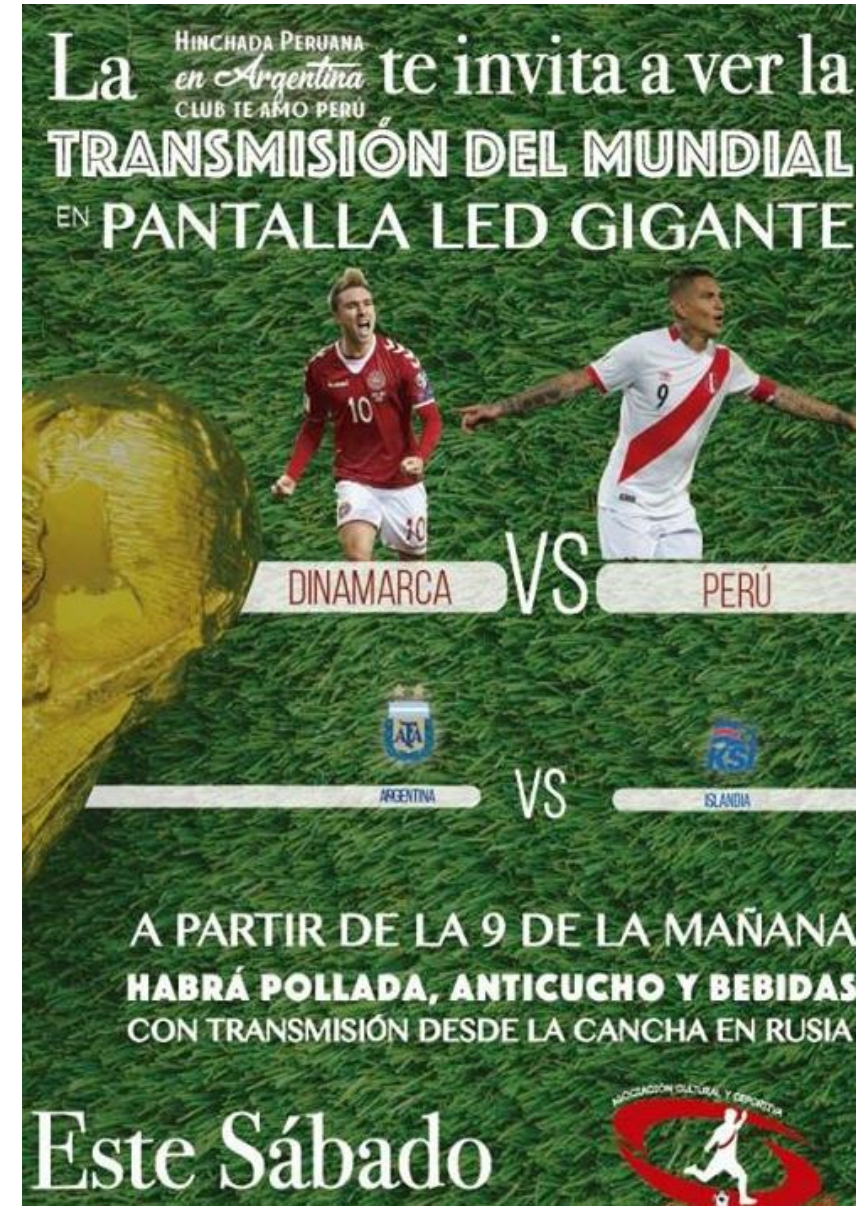

Figura 6: Captura de pantalla (15 de junio de 2018). Fuente: HINCHADA PERUANA EN ARGENTINA [OFICIAL] TE AMO PERU [Página de Facebook]. 


\section{Connotaciones de género}

María Soledad Balsas

15 de junio

\section{¿Dónde se juntan mañana a ver el partido?}

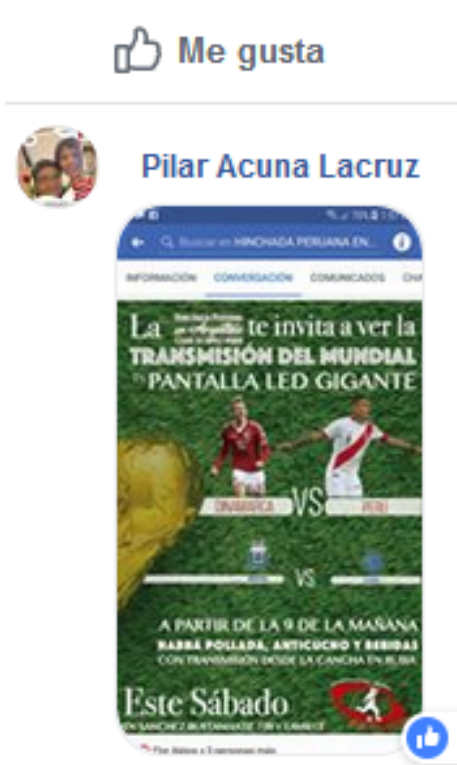

Me gusta - Responder - 4 sem

\section{A María Soledad Balsas Gracias!}

Una de mis intervenciones en el grupo estuvo orientada a identificar posibles lugares de reunión para trascender lo virtual y realizar el trabajo de campo presencial. Lo que sigue es la captura de pantalla del intercambio suscitado entre algunas y algunos participantes a partir de la respuesta que publicara otra miembro del grupo. En dicho diálogo están presentes connotaciones de género sobre lo que sería -o debería ser- el "telespectador modelo" del fútbol televisado. Lo enunciado evoca imágenes que, aunque privas de materialidad, están operando sin lugar a dudas en los modos en que hombres y mujeres consumen el fútbol por televisión. 
Magaly Gonzales Porque tan tempranooo is is is

Me gusta - Responder - 4 sem

Yeison Tafur Porqué el horario en Rusia es diferente porqué más va hacer XD jajaja

Me gusta - Responder - 4 sem

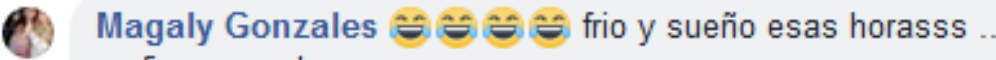
en fin que se le ase

Me gusta - Responder - 4 sem

Yeison Tafur Los amantes del fútbol no tienen horario,sueño ni frío 9

Me gusta - Responder - 4 sem

(2) Yeison Tafur Ya si algunos(as) dicen lo contrario, que sigan viendo sus novelas jajaja $\hat{\theta}$ e

Me gusta - Responder - 4 sem

Х Fabio Elmer Capo sin ofender ni agredir

Me gusta - Responder - 4 sem

Yeison Tafur Uhhh ahora un comentario en son de broma es agredir? Jajaja $\hat{=}$

Me gusta - Responder - 4 sem

2. Magaly Gonzales Ja.jaa nada que verr ... no veo novelass

Me gusta - Responder - 4 sem

Q Magaly Gonzales Todo bien

Yeison Tafur Magaly Gonzales jajaja el de arriba que no malentendida nada porqué solo fue en joda(sarcasmo) lo que dije jajaja 1 is igual los horarios de los partidos son re temprano pero bueno que podemos hacer Jajajaja

Me gusta - Responder - 4 sem

Figura 7: Captura de pantalla (15 de junio de 2018). Fuente: HINCHADA PERUANA EN ARGENTINA [OFICIAL] TE AMO PERU [Página de Facebook]. 
La consideración de lo visual en las entradas publicadas en los grupos de Facebook no puede a estas alturas obviar el difundido uso de "emojis" o emoticones y demás símbolos. Para "edulcorar" posiciones encontradas. Para ironizar. Para decir sin querer decir. Para expresar consenso. O simplemente para decorar.

Compartí a través del grupo de Facebook algunas de las fotos que saqué con mi celular durante el trabajo de campo presencial. Todas las imágenes fueron tomadas con el consentimiento oral de las y los protagonistas. En el caso de las y los niños, solicité el consentimiento de las y los adultos a su cargo. Algunas personas fotografiadas mostraron interés de ver las fotos, situación ante la cual consideré oportuno subirlas al grupo de referencia en Facebook.

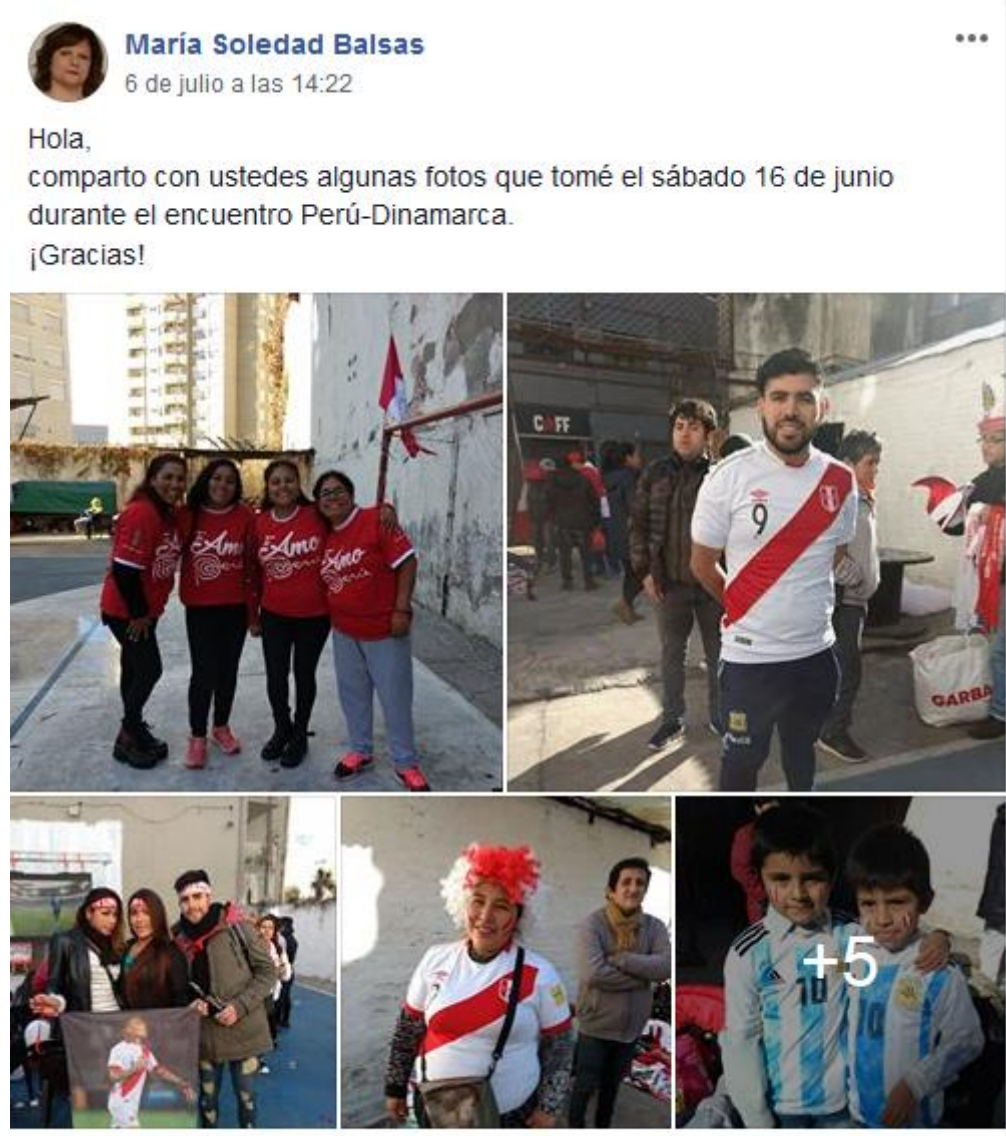

(1) Tú, Nora Mazziotti y 27 personas más

2 comentarios 1 vez compartido

Figura 8: Captura de pantalla (6 de julio de 2018). Fuente: HINCHADA PERUANA EN ARGENTINA [OFICIAL] TE AMO PERU [Página de Facebook]. 
La reacción publicada por una de las integrantes del club, miembro del grupo de Facebook, me brindó ulteriores oportunidades para reflexionar sobre el desempeño de lo visual en el análisis etnográfico.

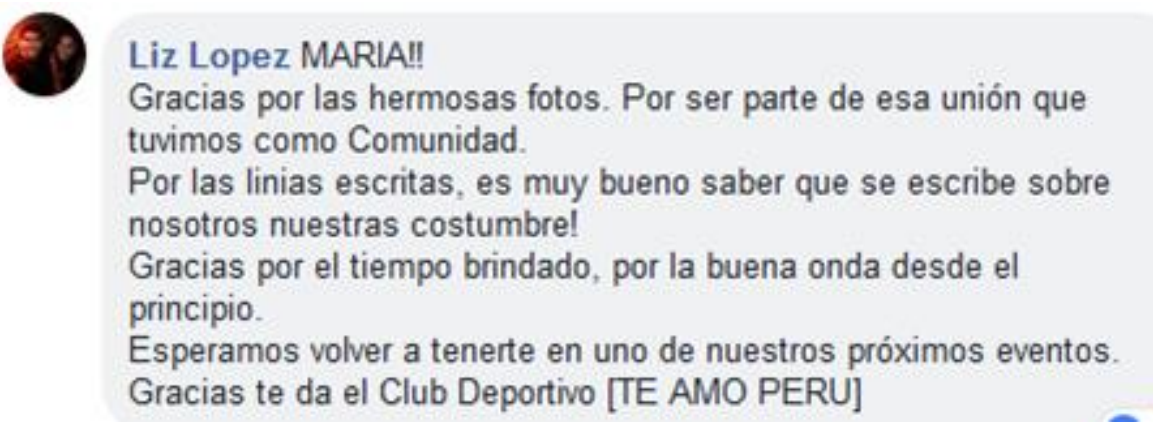

"[E]s muy bueno saber que se escribe sobre nosotros". Este testimonio evidencia la importancia otorgada a la escritura para legitimar objetos y sujetos de investigación. En mi caso particular, supuso cuestionar la relevancia de lo visual en relación a cada grupo migrante con el que trabajé. ¿Por qué el de las y los peruanos es un grupo más visualmente representable que el de las y los italianos? ¿O incluso el de las audiencias del fútbol gallego? ¿Qué supuestos subyacen en la importancia concedida a lo visual como modo de representación elegido? Estas preocupaciones se revelaron particularmente significativas al ponerlas en relación con las palabras de un cronista gráfico que presenció el evento en el que realicé el trabajo etnográfico presencial. Según dijo, había llegado hasta el predio en busca de una "nota de color" que plasmó en un fotorreportaje. De algún modo, sentí que, sin ser totalmente consciente de ello, yo estaba haciendo algo parecido...

\section{Consideraciones éticas}

En palabras de Márquez (2014), es preciso resguardar la identidad y la privacidad de las personas que intervienen directa $o$ indirectamente en nuestras investigaciones a través del anonimato. En el caso particular de los ambientes virtuales, ésto, en opinión de este autor, no sólo implica el uso de iniciales o códigos de identificación específicos sino también la alteración de cualquier detalle, la supresión de seudónimos y la ocultación de imágenes que pudieran hacer reconocible a la persona en cuestión. Aunque acordé con este enfoque en un principio, a 
medida que fui avanzando en el proceso de investigación lo encontré problemático por diversos motivos.

En términos de Pink (2007), las decisiones éticas siempre llevan implícitas relaciones de poder. En este mismo sentido, encontré desafiante para mis propias concepciones la idea según la cual "proteger a nuestros informantes resulta a veces abiertamente paternalista" (Pink, 2007: 163). En cambio, esta autora se muestra a favor de un enfoque de tipo colaborativo en el que la responsabilidad entre investigador/a y participantes sea compartida. Teniendo en cuenta estas cuestiones, decidí incluir las imágenes tal y como aparecen en este artículo porque consideré que al estar publicadas en un grupo de Facebook ya forman parte del dominio público. De hecho, la intención de publicarlas por esa vía antes que en otras tuvo la finalidad, también sugerida por Pink (2007), de sondear la recepción de las mismas entre las personas involucradas. Por otra parte, a pesar de que la perspectiva utilizada dista todavía de ser susceptible de ser considerada colaborativa, interpreto que no existarían elementos para considerar el uso reflexivo que propongo de imágenes propias y ajenas moralmente reprochable.

\section{A modo de cierre}

Tal como se desprende de los desarrollos anteriores, el análisis con y a partir de imágenes no resulta tan sencillo, como a veces se asume. Implica conocimientos técnicos y legales, desafíos metodológicos y posicionamientos éticos de diversa complejidad según el caso en cuestión. No obstante las dificultades para concretar un análisis etnográfico que reconozca la validez de lo visual como vía de conocimiento, en base a la experiencia más arriba analizada es posible concluir afirmando que vale la pena realizar el esfuerzo. No sólo para lograr una comprensión más acabada de las realidades que estudiamos sino, y sobre todo, para ejercer cierta vigilancia epistemológica sobre nuestros propios modos de ver y de posicionarnos como investigadores.

\section{Notas}

(1) Ley 11723, Regimen legal de la Propiedad Intelectual. Recuperado de http://servicios.infoleg.gob.ar/infolegInternet/anexos/40000-44999/42755/texact.htm 
(2) El uso de epígrafes provocadores y/o de textos reflexivos sobre el contexto de origen de las imágenes representa una de las formas posibles que asume el reconocimiento de su valor sin subordinarlo a la supremacía de lo escrito (Pink, 2007). En algunos casos, el epígrafe constituye incluso la única clave para la interpretación de la imagen (Woodward, 1993).

\section{Bibliografía}

Balsas, M. S. (2018). Televisión y participación política transnacionales. Las audiencias de televisión italiana en Buenos Aires. Buenos Aires: Prometeo.

Balsas, M. S. (2013). Las migraciones en los libros de texto. Tensión entre globalización y homogeneidad cultural. Buenos Aires: Biblos.

Barra, L.; Tarantino, M. y Tosoni, S. (2011). Etnografia virtuale e convergenza: spazi, tempi, discorsi e pratiche della TV sul web. En Tosoni, S. (comp.). Nuovi media e ricerca empirica. I percorsi metodologici degli internet Studies. Milán: Vita e Pensiero.

Guber, R. (2005). El salvaje metropolitano. Reconstrucción del conocimiento social en el trabajo de campo. Buenos Aires: Paidós.

Márquez, I. (2014). Ética de la investigación etnográfica en los cibermundos. En Anthropologica, 33, 111-135.

Pink, S. (2007). Doing visual ethnography. Images, media and representation in research. Londres: Sage.

Woodward, A. (1993). Do illustrations serve as instructional purpose in U.S. textbooks? En Britton, B.; Woodward, A. y Binkley, M. (comp.) Learning from textbooks. Nueva Jersey: Erlbaum. 